\title{
Arsenic trioxide reverses the chemoresistance in hepatocellular carcinoma: a targeted intervention of 14-3-3n/NF-kB feedback loop
}

Yongxin Qiu ${ }^{1 \dagger}$, Yi Dai ${ }^{2,3 \dagger}$, Chi Zhang ${ }^{1 \dagger}$, Ye Yang ${ }^{2 \dagger}$, Ming $\mathrm{Jin}^{2 \dagger}$, Wenqi Shan ${ }^{2}$, Jian Shen ${ }^{1}$, Ming Lu', Zhaoyang Tang ${ }^{1}$, Liang Ju', Yuting Wang ${ }^{2}$, Ruonan Jiao ${ }^{2}$, Yunwei Xia ${ }^{2}$, Guangming Huang ${ }^{1}$, Lihua Yang ${ }^{1}$, Yuan Li $i^{2,3 *}$,

Jianping Zhang ${ }^{1^{*}}$, Vincent Kam Wai Wong ${ }^{3^{*}}$ and Zhihong Jiang ${ }^{3^{*}}$

\begin{abstract}
Background: Multi-drug resistance (MDR) is one of the main obstacles for treatment of advanced/recurrent hepatocellular carcinoma (HCC). We have previously identified arsenic trioxide (ATO) as an effective metastasis/ angiogenesis inhibitor in HCC. Here, we further found that MDR-HCC cells were more sensitive to ATO.

Methods: The MDR-HCC cells were used as experimental models. Biological functions were investigated using cell transfection, polymerase chain reaction, western blot, southwestern blot, immunostaining, immunoprecipitation plus atomic fluorescence spectrometry, and so on.

Results: The MDR-HCC cells underwent high oxidative stress condition, and employed adaptive mechanisms for them to survive; while ATO abolished such mechanisms via targeting the 14-3-3n/nuclear factor kappa B (NF-kB) feedback Loop. Briefly, in MDR cells, the increase of ROS activated NF-kB signaling, which transcriptionally activated 14-3-3n. Meanwhile, the activation of NF-kB can be constitutively maintained by 14-3-3n. As a NF-kB inhibitor, ATO

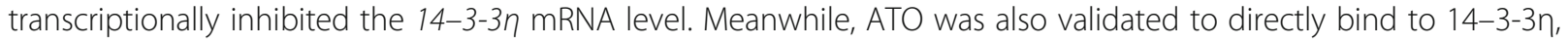
enhancing the degradation of $14-3-3 n$ protein in an ubiquitination-dependent manner. Knockdown of 14-3-3n reduced the ATO-induced reversal extents of drug resistance in MDR cells.
\end{abstract}

Conclusion: 14-3-3n/NF-KB feedback loop plays an important role in maintaining the MDR phenotype in HCC. Moreover, via targeting such feedback loop, ATO could be considered as a potential molecular targeted agent for the treatment of HCC.

Keywords: Hepatocellular carcinoma, Arsenic trioxide, Multi-drug resistance, 14-3-3n, Nuclear factor kappa B

\footnotetext{
* Correspondence: liyuan@njmu.edu.cn; zjpnjmu@aliyun.com; zjpnjmu@hotmail.com; kawwong@must.edu.mo; zhjiang@must.edu.mo †Yongxin Qiu, Yi Dai, Chi Zhang, Ye Yang and Ming Jin contributed equally to this work.

2Jiangsu Key Lab of Cancer Biomarkers, Prevention and Treatment, Jiangsu Collaborative Innovation Center For Cancer Personalized Medicine, School of Public Health, Nanjing Medical University, Nanjing, China

${ }^{1}$ The Second Affiliated Hospital of Nanjing Medical University, Nanjing, China

${ }^{3}$ State Key Laboratory of Quality Research in Chinese Medicine, Macau

Institute for Applied Research in Medicine and Health, Macau University of

Science and Technology, Macau, China
}

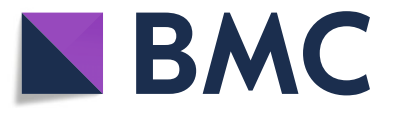

(c) The Author(s). 2018 Open Access This article is distributed under the terms of the Creative Commons Attribution 4.0 International License (http://creativecommons.org/licenses/by/4.0/), which permits unrestricted use, distribution, and reproduction in any medium, provided you give appropriate credit to the original author(s) and the source, provide a link to the Creative Commons license, and indicate if changes were made. The Creative Commons Public Domain Dedication waiver (http://creativecommons.org/publicdomain/zero/1.0/) applies to the data made available in this article, unless otherwise stated. 


\section{Background}

Hepatocellular carcinoma (HCC) is one of the most common malignant tumors and a leading cause of cancer-related mortality worldwide [1]. Surgical operation is the radical cure of HCC, nevertheless, most of the patients lose the surgical indications due to the advanced-stage of detection [2]. Currently, the transcatheter hepatic arterial chemoembolization (infusion of 5-fluorouracil, oxaliplatin, and/or doxorubicin) is the main non-operative methods for clinical treatment of advanced HCC [3]. However, the overall survival is not obviously ameliorated largely owing to the multiple-drug resistance (MDR) [4-6]. Therefore, unraveling the potential mechanisms, and identifying the novel therapeutic strategies to overcome MDR are urgently needed.

The 14-3-3 family (seven isoforms: $\beta, \gamma, \sigma, \varepsilon, \zeta, \eta$, and $\tau)$ are the phosphine/threonine binding proteins of approximate 28 to $33 \mathrm{kDa}$ acidic polypeptides [7]. By binding to the Ser-X-pSer or Ser-X-pThr (X represents an arbitrary amino acid) residue, they regulate multiple cellular functions, such as the regulation of cell cycle progression, the initiation and maintenance of DNA damage checkpoints, the prevention of apoptosis, and cytoskeletal dynamics [8]. Up to date, six members of 14-3-3 family proteins $(\beta, \gamma, \sigma, \varepsilon, \zeta$, and $\eta)$ have been identified to be involved in promoting the growth, angiogenesis, and metastasis of HCC [9]. Among them, two members $(\zeta$ and $\sigma$ ) of $14-3-3$ proteins have also been identified to be associated with chemotherapy/molecular target drug resistances $[10,11]$. In particular, our previous study revealed that, by forming a positive feed-back loop with extracellular signal-regulated kinase $1 / 2$ (ERK1/2), 14-3-3ך effectively promotes the growth, angiogenesis, and sorafenib resistance [12]. Therefore, in our present study, we continued to reveal the effects and underlying mechanisms of $14-3-3 \eta$ on MDR in HCC, and further aimed to find out potential interventions.

\section{Methods \\ Regents}

Arsenic trioxide (ATO, $\mathrm{As}_{2} \mathrm{O}_{3},>99.0 \%$ purity), 5-fluorouracil (5- $\mathrm{Fu}, \mathrm{C}_{4} \mathrm{H}_{3} \mathrm{FN}_{2} \mathrm{O}_{2},>99.0 \%$ purity), oxaliplatin (L-OHP, $\mathrm{C}_{8} \mathrm{H}_{14} \mathrm{~N}_{2} \mathrm{O}_{4} \mathrm{Pt}$, > 99.0\% purity), and doxorubicin (DOX, $\mathrm{C}_{27} \mathrm{H}_{29} \mathrm{NO}_{11} \cdot \mathrm{HCl}$, > 98.0\% purity) were purchased from Sigma-Aldrach (Shanghai, China). The BAY-117082 and MG-132 were purchased from Beyotime Co. Ltd. (Haimeng, China). The stattic, topotecan, and ML-385 were obtained from Med-Chem-Express (Shanghai, China). All other reagents used were of analytical grade or the highest grade available.

\section{Cell culture and construction of 5-Fu-resistant cells}

HCC cell line, Bel-7402 was obtained from Institute of Biochemistry and Cell Biology, Chinese Academy of
Science (Shanghai, China), and was STR identified by China Center for Type Culture Collection (Wuhan, China). Cells were maintained in a $37^{\circ} \mathrm{C}$ humidified incubator with 5\% $\mathrm{CO}_{2}$ in RPMI-1640 medium (Gibco, Grand Island, NY), supplemented with $10 \%$ fetal bovine serum (FBS), $100 \mathrm{U} / \mathrm{ml}$ penicillin, $100 \mu \mathrm{g} / \mathrm{ml}$ streptomycin (Gibco). To obtain 5-Fu-resistant cells (Bel/5-Fu), as described previously [13-15], the Bel-7402 cells were cultured in RPMI-1640 medium with $2 \mu \mathrm{M}$ of 5 -Fu for 5 days. After an exponential growth was again reached in these treated cells, RPMI-1640 medium with $20 \mu \mathrm{M}$ of 5 - Fu was added and cells was cultured for another period of time. Likewise, the cells were gradually exposed to stepwise increasing concentrations for a harsh selection. After a continuous induction of approximately 5 months, Bel $/ 5-\mathrm{Fu}$ cells were successfully established after a sustained growth and steady passage in the RPMI-1640 medium contained $200 \mu \mathrm{M}$ of 5 -Fu.

\section{Cell transfection}

Scrambled and pcDNA-3.1-14-3-3ך-Flag were synthesized by Generay Biotech (Shanghai, China); while 14-3-3n- and NF-kB/p65 siRNA were purchased from Santa Cruz Biotechnology (http://datasheets.scbt.com/sc-43581.pdf, and https://datasheets.scbt.com/sc-29410.pdf) [12, 16]. Cells were transiently transfected via lipofectamine 2000 reagent (Invitrogen, Carlsbad, USA), according to the manufacturer's protocol (Note: plasmids used: $5 \mathrm{ng} / \mathrm{ml}$. siRNAs used: $20 \mathrm{nM}$ ). After transfection, the cells were cultured in fresh medium supplemented with 10\% FBS for another 24 $\mathrm{h}$ before being used for other experiments.

Calculation of the $50 \%$ inhibitory dose $\left(\mathrm{IC}_{50}\right)$ Cell viabilities were determined via using a CCK-8 kit [12]. The $\mathrm{IC}_{50} \mathrm{~S}$ were calculated via a graph-pad 6.0 software (CA, USA). For each test, the inhibition ratio was determined via a three-parameter dose-response equation and calculated with a non- linear regression. A sigmoidal curve was generated and the $\mathrm{IC}_{50}$ value was acquired. The ordinate represented inhibition ratio, while the abscissa represented the $\log$ (concentrations). The calculation mode used was "log (inhibitor) vs. response (three parameters)", and results exhibited represented "best-fit values" \pm "std. errors".

\section{Determination of the intracellular ROS}

The ROS Assay Kit was purchased from Beyotime Co. Ltd. As we described previously, treated cells were incubated in triplicate with DCFH-DA at $37^{\circ} \mathrm{C}$ for 30 min, then the fluorescent signal was observed using a fluorescence microscope (Olympus, Tokyo, Japan), and the DCFH fluorescence intensity was measured by a multi-well plate reader (Bio-Rad) at an excitation wavelength of $488 \mathrm{~nm}$ and an emission wavelength of $525 \mathrm{~nm}[17,18]$. 


\section{Quantitative real-time polymerase chain reaction (qRT-PCR)}

The isolation of total RNA, the transcription of RNA to cDNA, and the performance of qRT-PCR with Applied Biosystems 7300HT machine were all according to our previous study [19]. The primers for $14-3-3 \eta$ were F: 5'-cctgcctcttagccaaac-3', and R: 5' -ctcctgcttcttcatcctg-3'. The $\beta$-actin was amplified to ensure cDNA integrity and to normalize expression. Fold changes in expression of each gene were calculated by a comparative threshold cycle $(\mathrm{Ct})$ method using the formula $2^{-(\Delta \Delta \mathrm{Ct})}$.

\section{Western blot (WB) and southwestern blot (SB)}

Extraction of total/nuclear proteins, measurement of their concentrations with BCA kit, and SDS-PAGE followed by transferring the protein to PVDF membranes were all according to our previous study [20]. The primary antibodies used were: $14-3-3 \eta, p-I K K \beta$, p-IкB $\alpha$, p-p65 (Cell Signaling Technology, MA, USA, dilutions, 1: 1000), Flag, and $\beta$-actin (Beyotime Co. Ltd., the dilutions, 1: 2000). The biotin-labeled probe (con-

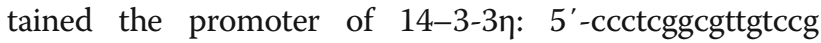
cggc-3') was synthesized by Zhuoli Biotechnology Co., Ltd. (Shanghai, China). The immune complexes were detected by enhanced chemiluminescence (Cell Signaling Technology) and densitometric analysed via an image-pro-plus 6.0 software (Media Cybernetics, Georgia, USA) [21].

\section{Immunostaining}

After cells were fixed, permeablized, and blocked as described previously [12], they were incubated with rabbit-anti-p65 (Cell Signaling Technology, dilution, 1: 200) antibody at $4{ }^{\circ} \mathrm{C}$ overnight, followed by incubating for $1 \mathrm{~h}$ with FITC-conjugated anti-rabbit secondary antibody (Beyotime Co. Ltd.; dilutions, 1: 500). The nuclei were stained by adding 4', 6-diamidino-2-phenylindole (DAPI, Beyotime Co. Ltd). Then, cells were observed and pictured under a Zeiss-700B laser scanning confocal microscope (Zeiss Co. Ltd., Oberkochen, Germany).

\section{Immunoprecipitation plus atomic fluorescence spectrometry (IP-AFS)}

After Bel/5-Fu cells were pre-treated by 0 or $20 \mu \mathrm{M}$ of MG-132, for $2 \mathrm{~h}$, they were exposed to $10 \mu \mathrm{M}$ of ATO for $6 \mathrm{~h}$. Then, such cells were extracted for $30 \mathrm{~min}$ with immunoprecipitation lysis buffer (Beyotime Co. Ltd). After centrifugation of the preparations, $100 \mu \mathrm{g}$ of total

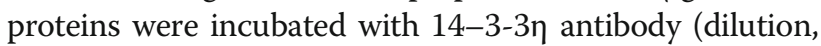
1: 100) at $4{ }^{\circ} \mathrm{C}$ overnight. Then the protein-antibody complexes were incubated with IgG sepharose beads (Beyotime Co. Ltd) at $4{ }^{\circ} \mathrm{C}$ for another $12 \mathrm{~h}$. After then, the supernatants were removed (positive control) and the beads were washed for three times (residual supernatants, served as a negative control), boiled to remove protein from the beads and extracted by $5 \mathrm{M}$ of $\mathrm{HCl}$ (experimental group). Then we added $5 \mathrm{M}$ of $\mathrm{KOH}$ to the extraction to adjust the $\mathrm{pH}$ between 2.0-7.0.

For hydride generation atomic fluorescence spectrometry, we used the dual channel atomic fluorescence spectrometer with special arsenic high intensity hollow cathode lamp (Titan Instruments Co, Beijing, China). The instrument working parameters were: pre-reducing agent $(3.5 \% \mathrm{HCl}+0.1 \%$ ascorbic acid $+0.1 \%$ thiourea $)$, reducing agent (1\% KBH4+ 0.175\% KOH), carrier gas (argon gas), PMT voltage $(260 \mathrm{~V})$, primary current $(50-80 \mathrm{~mA})$, atomizer height $(8 \mathrm{~mm})$, carrier gas flow rate $(500 \mathrm{ml} / \mathrm{m})$, shield gas flow rate $(800 \mathrm{ml} / \mathrm{m})$, sampling time $(9 \mathrm{~s})$, delay period ( $2 \mathrm{~s})$, measurement mode (peak area), and determination method (standard curve, STD).

\section{Statistical analysis}

Data were presented as the means \pm SD. The differences were analyzed via using student's t test, one-way analysis of variance followed by Dunnett's $t$ test, or two-way analysis of variance followed by Sidak's multiple comparisons test via a graph-pad 6.0 software. The $p$ values $<0.05$ were considered statistically significant.

\section{Results}

\section{Characterization of 5-Fu-resistant HCC cells}

Cell viability assays demonstrated that the 5 -Fu-resistant Bel-7402 cells (Bel/5-Fu) were more resistant to chemotherapeutic drugs (5-fluorouracil, oxaliplatin, and doxorubicin) than its parental cells, Bel-7402. The $\mathrm{IC}_{50 \mathrm{~s}}(\mu \mathrm{M})$ of these three drugs for Bel-7402 and Bel/5-Fu cells were: 5-fluorouracil ( 95.34 vs. 2243, Fig. 1a), oxaliplatin (51.15 vs. 314.5, Fig. 1b), and doxorubicin (7.43 vs. 31.28, Fig. 1c). Moreover, compared with Bel-7402 cells, increased expressions of MDR related genes, such as MDR1 and MRP1 were observed in Bel/5-Fu cells (Additional file 1: Figure S1). So, we confirmed that the $\mathrm{Bel} / 5-\mathrm{Fu}$ cells obtained the MDR phenotype. In addition, the intracellular ROS level (as determined by DCF-fluorescence) was elevated in Bel/5-Fu cells in comparison with its parental counterparts (Fig. 1d and e). Thus, we further suggested that Bel/5-Fu cells were exposed to relative higher oxidative stress condition, which further facilitated these cells to employ the adaptive mechanisms for survival in an inhospitable microenvironment.

Effects of $14-3-3 \eta$ on anti-oxidation and MDR in HCC cells We previously found that in HCC cells, overexpression

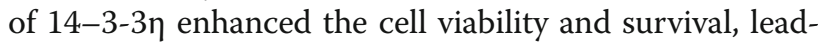
ing to the resistance to sorafenib [12]. Here, in Bel/5-Fu cells, the expressions of $14-3-3 \eta$ were significantly higher than those in parental Bel-7402 cells (Fig. 2a). So, we firstly validated the relationship between 14 and $3-3 \eta$ 

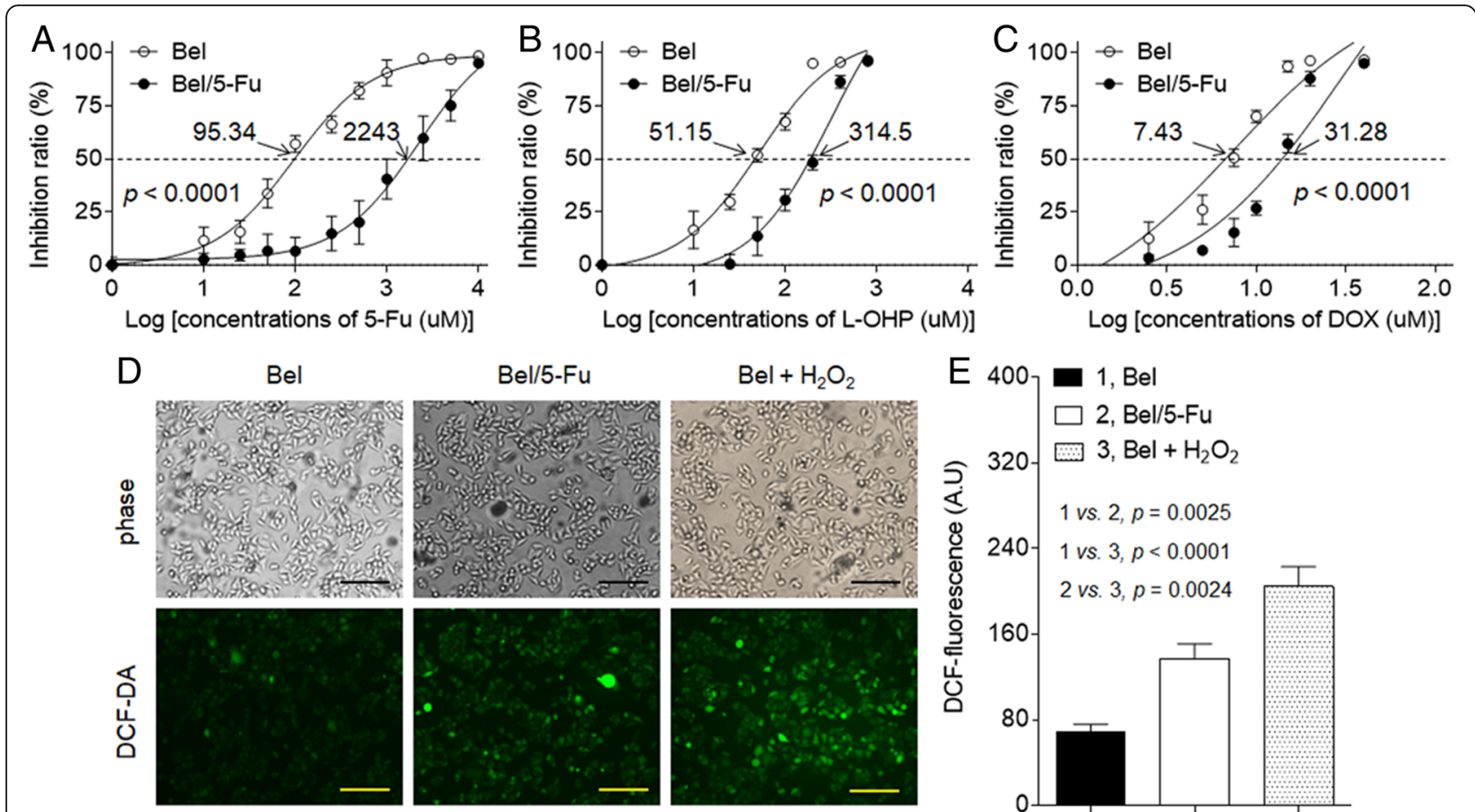

Fig. 1 Characterization of 5-Fu-resistant HCC cells: a to c Bel-7402 or Bel/5-Fu cells were treated by different concentrations of 5-fluorouracil (0 to $\left.10^{4} \mu \mathrm{M}\right)$, oxaliplatin $\left(0\right.$ to $\left.10^{3} \mu \mathrm{M}\right)$, or doxorubicin $\left(0\right.$ to $\left.10^{2} \mu \mathrm{M}\right)$ for $24 \mathrm{~h}$, respectively. The cell viability was determined in triplicate, and the $I \mathrm{C}_{50 \mathrm{~s}}$ were calculated. $\mathbf{d}$ and $\mathbf{e}$ The intracellular ROS levels were determined in triplicate (the $\mathrm{H}_{2} \mathrm{O}_{2}$-treated Bel-7402 cells were used as a positive control; Bars $=250 \mu \mathrm{m}$ )

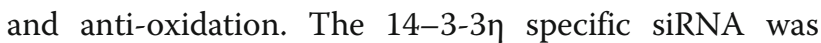
transfected into Bel/5-Fu cells. As shown in Fig. 2b and c, knockdown of $14-3-3 \eta$ further elevated the spontaneous intracellular ROS level and inhibited cell viability. In contrast, overexpression of $14-3-3 \eta$ by transfecting the 14$3-3 \eta$ plasmids into Bel-7402 cells significantly attenuated the hydrogen peroxide-induced ROS generation (Fig. 2d) and improved the cell survival (Fig. 2e). Similar results were also confirmed in another HCC cell line (Additional file 1: Figure S2).

Next we investigated if $14-3-3 \eta$ could contribute the drug-resistance in Bel/5-Fu cells. As shown in Additional

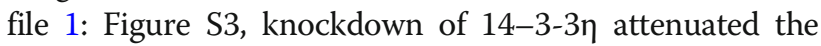
expressions of MDR1 and MRP1 mRNAs. Meanwhile, the $\mathrm{IC}_{50 \mathrm{~s}}(\mu \mathrm{M})$ of 5-fluorouracil, oxaliplatin, and doxorubicin

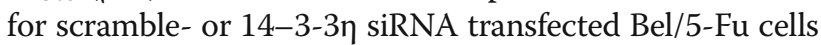
were: 1381 vs. $298.8,170.3$ vs. 70.1 , and 25.09 vs. 11.91, respectively (Fig. 3a to c). In addition, we also determined if $14-3-3 \eta$ could induce the MDR in parental Bel-7402 cells. As shown in Fig. 3d to f, the $\mathrm{IC}_{50 \mathrm{~s}}(\mu \mathrm{M})$ of the above-mentioned three chemothera-

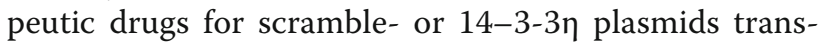
fected Bel-7402 cells were 67.12 vs. $133.8,34.31$ vs. 66.14 , and 5.809 vs. 9.089. Similar results were also confirmed in another HCC cell line (Additional file 1: Figure S4). Collectively, these results revealed that

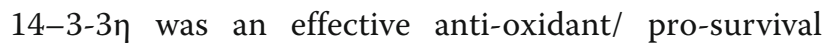
factor, leading to the MDR of HCC cells.

\section{Potential mechanisms underlying 14-3-3n-induced/ maintained MDR}

Then, we focused on why the 14-3-37 was overexpressed in MDR-HCC cells. Via sequence alignment, we found four DNA binding elements located at the promoter region of $14-3-3 \eta$ gene. Those were the anti-oxidative response element (ARE, for NRF2), hypoxia response element (HRE, for HIF-1 $\alpha$ ), GAS (for STAT-3), and $\kappa B$ sequence (for NF-kB) (Fig. 4a). Interestingly, these four transcriptional factors play key roles in inducing/maintaining the anti-oxidation and MDR in HCC [22-24]. As shown in Fig. 4a, treatment of Bel/5-Fu cells with ML-385 (NRF2 inhibitor), topotecan (HIF-1 $\alpha$ inhibitor), stattic (STAT-3 inhibitor), or BAY-117082 (NF-kB inhibitor) decreased the expression of $14-3-3 \eta$ mRNA from $100 \%$ (medium control group) to $79.38,67.19,51.57$, and $38.27 \%$, respectively.

The signal transductions among NRF2, HIF-1 $\alpha$, STAT-3, and NF- $\mathrm{kB}$ are complicated (involving both positive and negative regulations). Since the inhibition

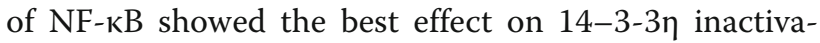
tion (Fig. 4a), we then determined the relationships

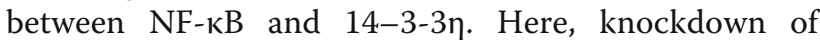
$\mathrm{NF}-\mathrm{\kappa B}$ in $\mathrm{Bel} / 5-\mathrm{Fu}$ cells attenuated the activation of 


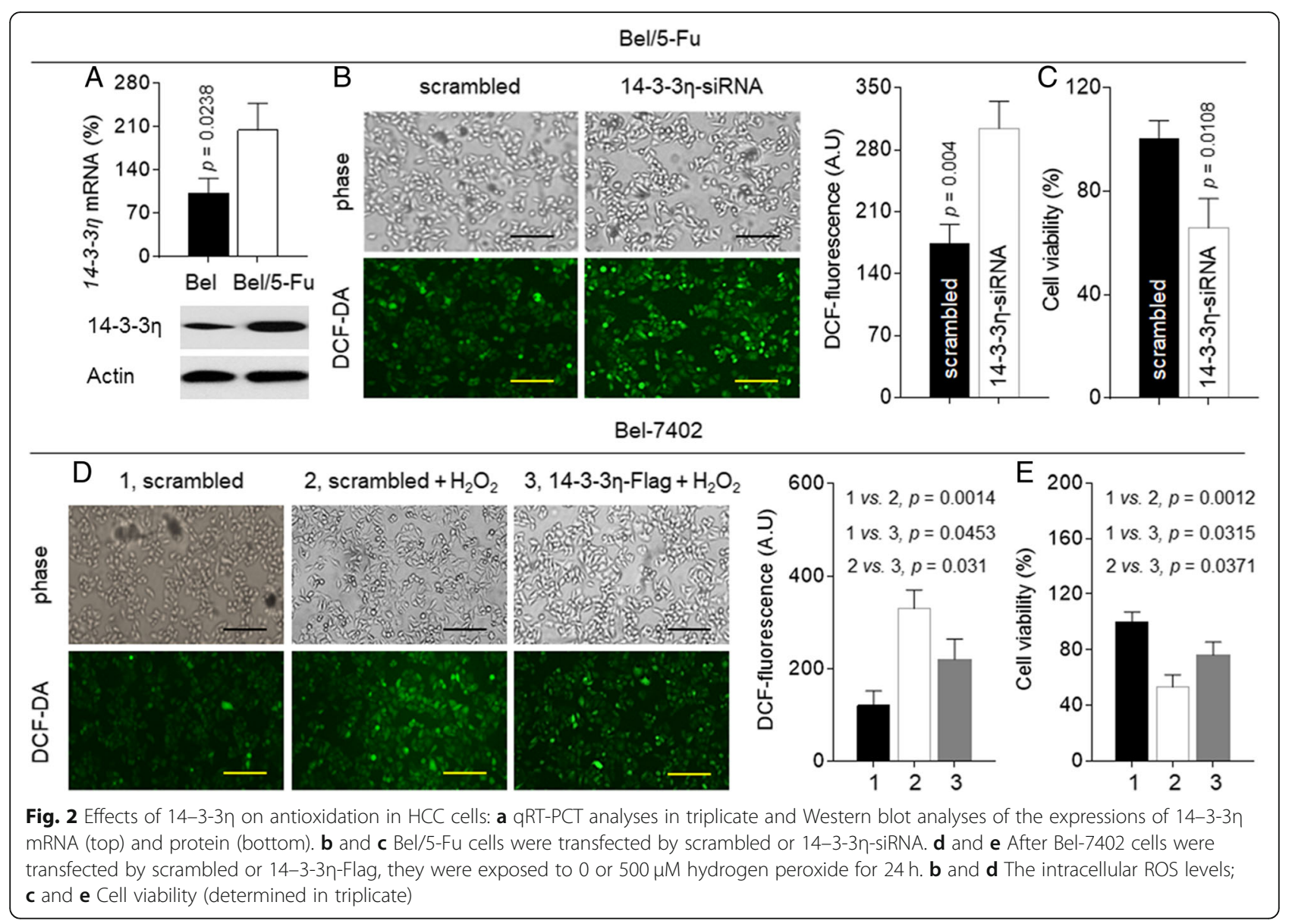

$\mathrm{NF}-\mathrm{kB} / \mathrm{p} 65$ and $14-3-3 \eta$. Indeed it would inhibit the binding of probe (containing the $\mathrm{\kappa B}$ sequence located in $14-3-3 \eta$ promoter) to nuclear NF- $\mathrm{kB} / \mathrm{p} 65$ (Fig. $4 \mathrm{~b}$ to $\mathrm{d}$ ), and decreased the $\mathrm{IC}_{50 \mathrm{~s}}(\mu \mathrm{M})$ of 5 -fluorouracil, oxaliplatin, and doxorubicin (978.8 vs. 333.1, 143.4 vs. 57.96 , and 22.765 vs. 13.42, respectively, Fig. 4e). Meanwhile, we also confirmed that NF- $\kappa B$ was an up-stream regulator of $14-3-3 \eta$ in other $\mathrm{HCC}$ cell lines (Additional file 1: Figure S5).

Next, we further investigated whereby $14-3-3 \eta$ induced/maintained MDR. Interestingly, studies revealed that some other 14-3-3 isoforms (such as $\varepsilon$ and $\zeta$ ) can also maintain the activity of NF- $\mathrm{kB}$ via enhancing the phosphorylation of NF-kB/p65 in HCC $[25,26]$. In the

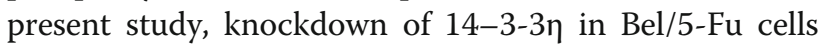
markedly suppressed the expression and/or nuclear translocation of $\mathrm{p}-\mathrm{IKK} \beta, \mathrm{p}-\mathrm{I} \mathrm{KB} \alpha$, and $\mathrm{p}-\mathrm{NF}-\mathrm{\kappa B} / \mathrm{p} 65$ (Fig. $5 \mathrm{a}$ to c). On the contrary, overexpression of 143-3 $\eta$ in Bel-7402 cells showed the opposite effects (Fig. 5d to f). Similar results were also confirmed in other HCC cell lines (Additional file 1: Figure S6). Collect-

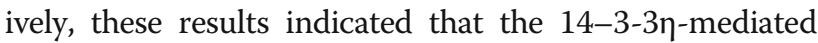
MDR in HCC cells was regulated by forming a positive feed-back loop with NF-kB.
Identification of ATO as a characteristic 14-3-3n inhibitor in HCC cells

Based on our previous findings, ATO is an effective NF-kB inhibitor in HCC cell line, MHCC97H [27, 28]. Here, as shown in Fig. 6a, ATO decreased the expression/

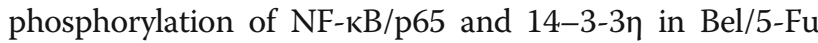
cells, suggesting that ATO might down-regulate $14-3-3 \eta$ at the transcriptional level via the inhibition of NF- $\mathrm{kB}$. Meanwhile, via a computer docking, we also found that ATO specifically bound to $14-3-3 \eta$ protein, but not to other six 14-3-3 isoforms (Fig. 6b, and Additional file 1: Figure S7). Thus we adopted a novel approach by combining both IP and AFS techniques to reveal the interaction

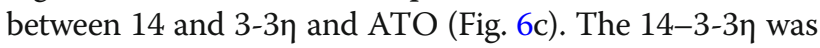
immunoprecipitated with its specific antibody and its ATO-binding status was determined by AFS to investigate if the immunoprecipitation complex contained ATO. As shown in Fig. 6d and Additional file 1: Figure S8, the concentration of ATO in positive control group (total protein)

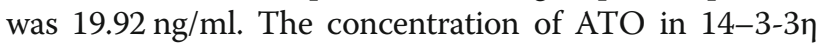
immunoprecipitated complex (experimental group) was $5.83 \mathrm{ng} / \mathrm{ml}$. We almost did not detect the presence of ATO in negative control groups. Previous study revealed that ATO could target (bound to) and in turn induced the 

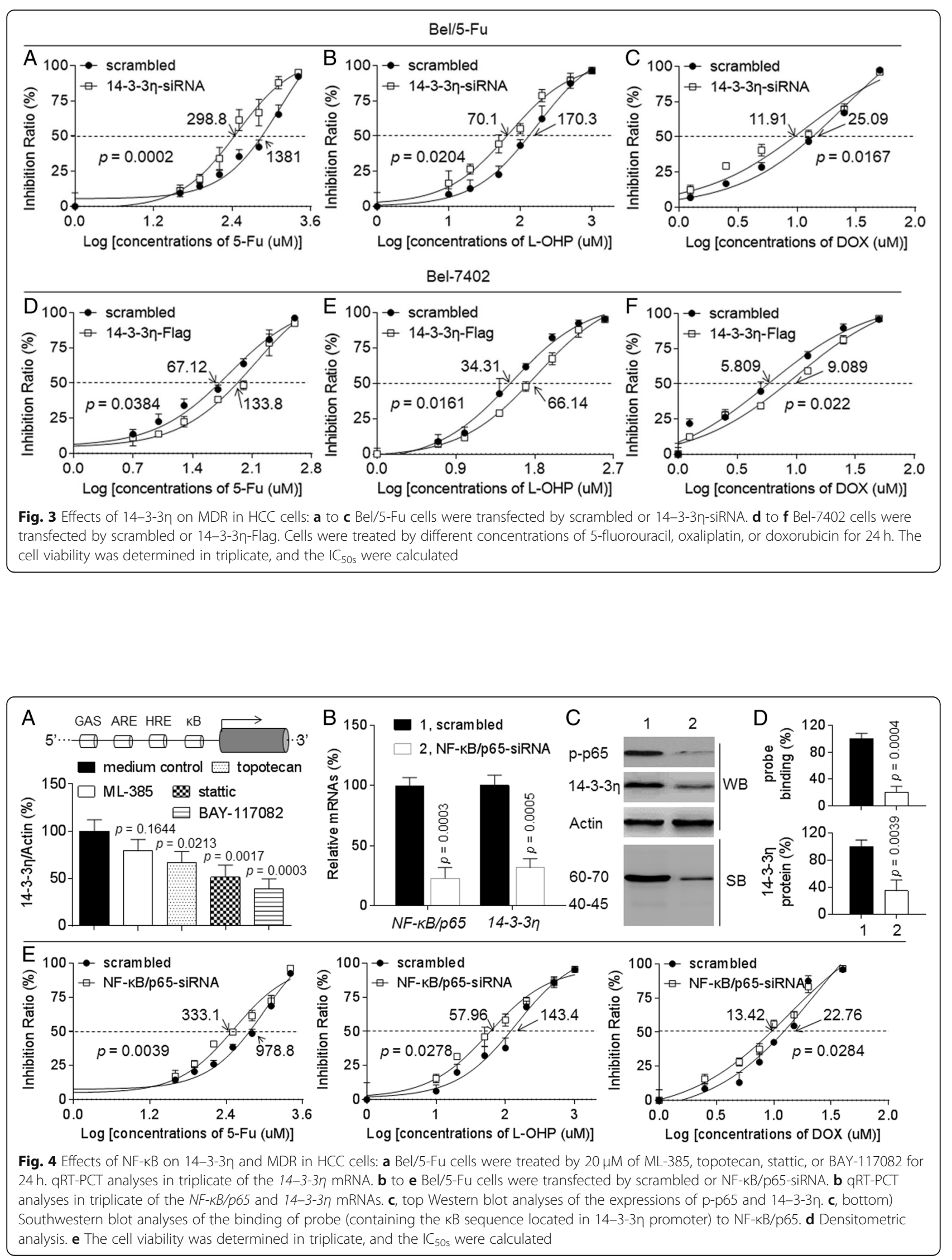

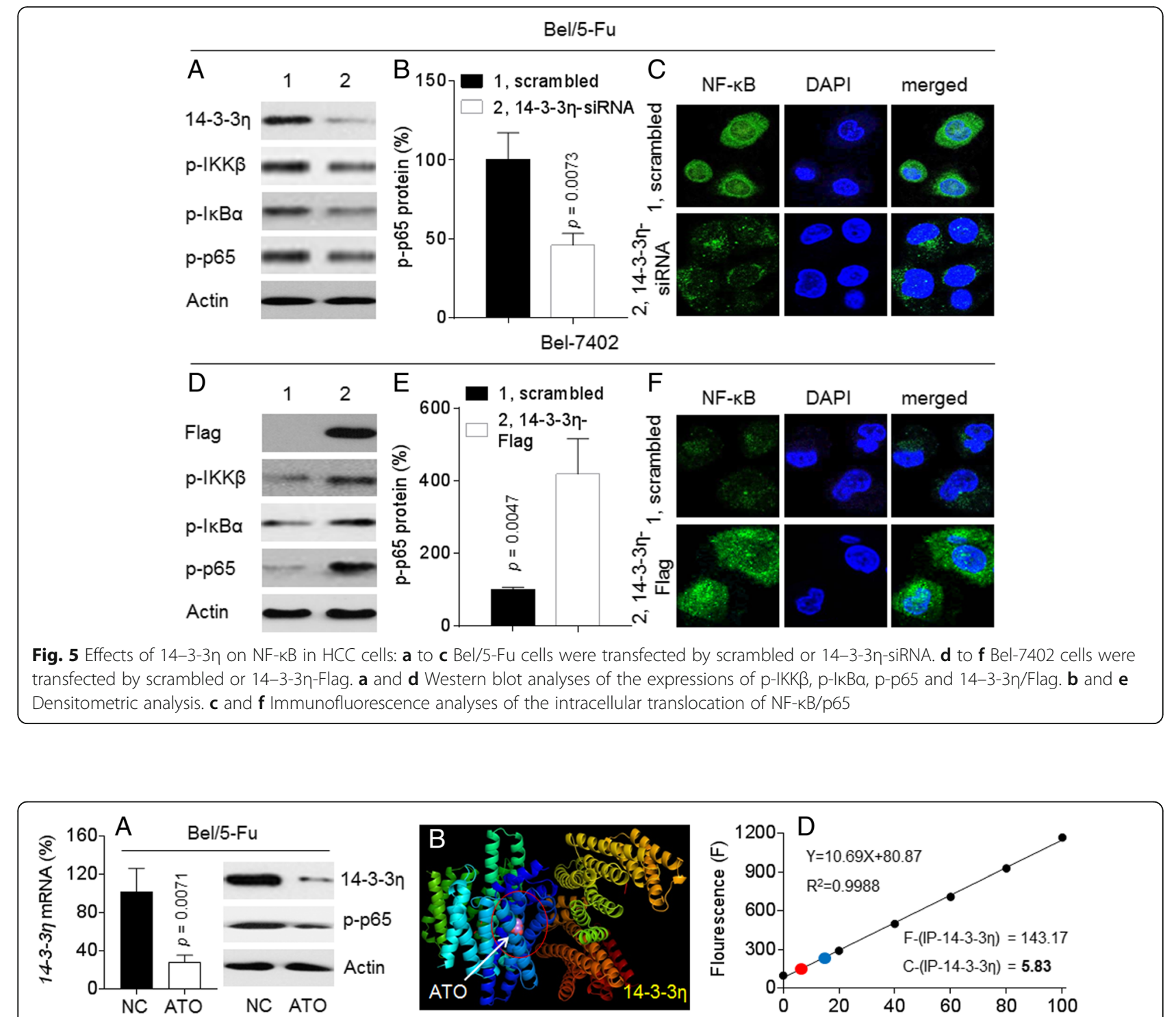

\section{Step-1} total protein

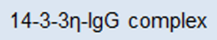

14-3-3n-lgG-beads complex
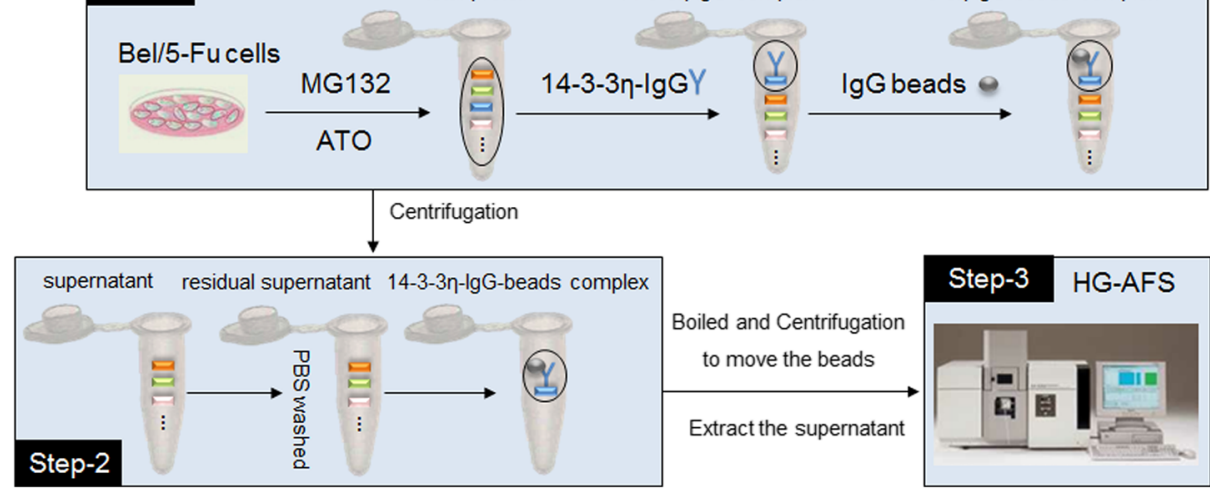

E MG-132 ATO+MG-132

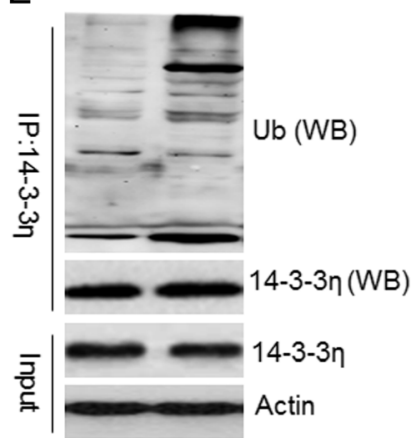

Fig. 6 Relationships between ATO and 14-3-3n: a Bel/5-Fu cells were treated by $10 \mu \mathrm{M}$ of ATO for $24 \mathrm{~h}$. qRT-PCT analyses in triplicate (left) and Western blot (right) analyses of the expressions of 14-3-3n and/or p-p65. b PyMol software analyses of the binding of ATO to 14-3-3n. cThe procedure of IP-AFS. $\mathbf{d}$ and e After Bel/5-Fu cells were pre-treated by $20 \mu \mathrm{M}$ of MG-132 for $2 \mathrm{~h}$, they were exposed to $10 \mu \mathrm{M}$ of ATO for $6 \mathrm{~h}$. The 14-3-3n was immunoprecipitated with the specific antibody. $\mathbf{d}$ AFS analyses of the concentration of ATO in 14-3-3n-immunoprecipitation complex. e Western blot analyses of the expression of ubiquitin in 14-3-3n-immunoprecipitation complex 
degradation of PML-RAR protein [29]. Here, we found that ATO treatment enhanced the ubiquitination of 14-3-3 $\eta$ in Bel/5-Fu cells (Fig. 6e). Collectively, these results indicated that, ATO inhibited the $14-3-3 \eta$ at both transcriptional (indirectly, might via blocking NF- $\mathrm{kB}$ ) and post-transcriptional (directly, might via targeting and inducing the ubiquitination and degradation of $14-3-3 \eta$ ) modifications in HCC cells.

\section{4-3-3n was involved in ATO-reversed MDR}

As shown in Additional file 1: Figure S9, the Bel/5-Fu cells were more sensitive to ATO in comparison with Bel-7402 cells [the IC50s $(\mu \mathrm{M})$ were 17.69 vs. 32.46]. In addition, ATO-treatment decreased the expressions of MDR1 and MRP1 mRNAs (Additional file 1: Figure S10). Based on the above-mentioned results, we further suggested that, the relative higher level of $14-3-3 \eta$ in $\mathrm{Bel} /$ 5 -Fu cells might be the mechanisms whereby they were more sensitive to ATO. For cancer chemotherapy, ATO was used with concentration of approximately $10.8 \mu \mathrm{M}$ in the patients' plasma [30]. Moreover, we previously revealed that $10 \mu \mathrm{M}$ of ATO had no detectable cytotoxicity in normal hepatic or in non-drug resistant HCC cells $[27,28]$. In the current study, the effects of $10 \mu \mathrm{M}$ of ATO on the viabilities compared with non ATO-treated in Bel-7402 and Bel/5-Fu cells were 90.67 and 83.3\%, respectively (Additional file 1: Figure S11). So we chose this concentration of ATO for further investigation.
Here, the scramble-transfected $\mathrm{Bel} / 5-\mathrm{Fu}$ cells were treated by different concentrations of 5-fluorouracil, oxaliplatin, and doxorubicin, in the absence or presence of $10 \mu \mathrm{M}$ ATO. The $\mathrm{IC}_{50 \mathrm{~s}}(\mu \mathrm{M})$ of for chemotherapy alone group and chemotherapy combined with ATO treatment group were: 5-fluorouracil (1567 vs. 233.4), oxaliplatin (198 vs. 61.55), and doxorubicin (20.23 vs. 7.546, Fig. $7 \mathrm{a}$ to c). However, the $\mathrm{IC}_{50 \mathrm{~s}}(\mu \mathrm{M})$ of chemotherapy alone group and chemotherapy combined with ATO treatment group were: 5-fluorouracil (276.4 vs. 166.4 ), oxaliplatin (34.5 vs. 24.09), and doxorubicin

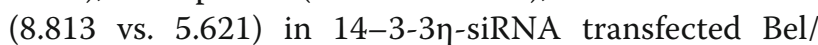
5-Fu cells (Fig. 7d to f).

In scramble-transfected cells, co-treatment with ATO induced the reversal extents of drug resistance to $85.1 \%$ (5-fluorouracil), 68.9\% (oxaliplatin), and 62.7\% (doxo-

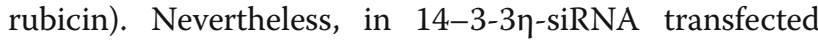
cells, these reversal extents were further dropped to $39.79 \%$ (5-fluorouracil), 30.17\% (oxaliplatin), and 36.2\%

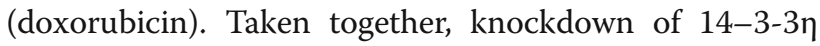
reduced the ATO-induced reversal extents of drug resistance, suggesting that $14-3-3 \eta$ may be participated in the ATO-reversed MDR in HCC cells.

\section{Discussion}

In current study, we used three first line chemotherapeutic agents, 5-fluorouracil, oxaliplatin, and doxorubicin. Classically, these three drugs inhibit the HCC

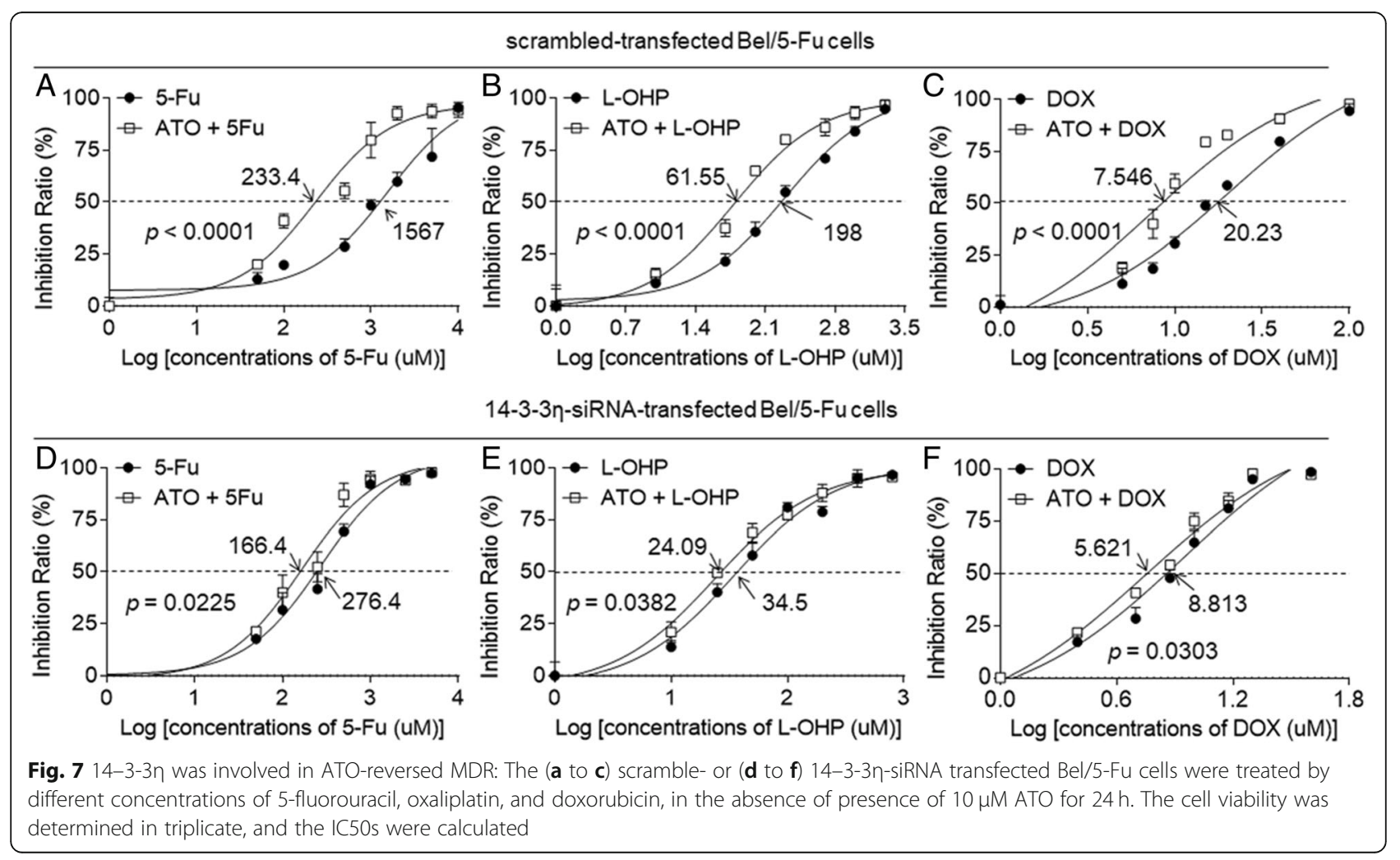


progression through their respective pathways. 5-fluorouracil is a thymidylate synthase inhibitor and its metabolites can be incorporated into DNA, thus influence cell proliferation [31]. Oxaliplatin can covalently bind to guanine on the DNA chain and thus, block the replication and transcription of DNA [32]. Doxorubicin directly acts on DNA and inhibits DNA polymerase and thus can interfere both DNA and RNA synthesis [33]. Besides, 5-fluorouracil, oxaliplatin and doxorubicin are also reported to exhibit cytotoxic effect through increasing the ROS generation [34, 35]. Indeed, their effects on DNA damage and cell apoptosis can also be enhanced via oxidative stress. Furthermore, current study showed that Bel/5-Fu cell exhibited a relative higher level of ROS and possessed a capacity of anti-oxidation in comparison with Bel7402 cells. So, destroying the antioxidative capacity of drug-resistant cells could be expected to become a new approach to reverse the MDR.

NF- $\mathrm{KB}$ signaling pathway plays a key role in controlling the initiation and progression of human cancer $[16,20]$. More recently, it has become clear that NF- $\kappa B$ signaling also has a critical role in chemotherapy resistance [36]. Here we found that, the elevated intracellular ROS level contributed to the activation of NF- $\mathrm{kB}$ in Bel/5-Fu cells (Additional file 1: Figure $\mathrm{S} 12)$. NF- $\mathrm{kB}$ provides a mechanistic link between inflammation and cancer, and is a major factor controlling the ability of both pre-neoplastic and malignant cells to resist apoptosis-based tumor-surveillance mechanisms [37]. It might also regulate tumor angiogenesis and invasiveness, and the signaling pathways that mediate its activation, so as to become an attractive target for new chemo-preventive and chemo-therapeutic approaches [38].

The regulations of NF- $\mathrm{KB}$ by arsenic are very complex. In normal cells, the regulatory effect of arsenic on NF- $\mathrm{kB}$ depends on the dose of exposure. Generally, low dose of arsenic can activate NF- $\mathrm{kB}$ by inducing a moderate oxidative stress, while high dose of arsenic causes an excessive oxidative stress, leading to the inhibition of NF-KB [20, 21]. For cancer cells, our previous studies found that, via the demethylation-activation of microRNA491, ATO effectively inhibited the activation of NF- $\mathrm{kB}$ in HCC $[27,28]$. Our present study further revealed that, the targeted intervention of $14-3-3 \eta$ also contributed to the ATO-induced inactivation of NF- $\mathrm{kB}$. So, our results expand the understanding of the anti-cancer potential of ATO by identifying a novel mechanism whereby the ATO inhibited NF-kB.

ATO has been recognized as the first-line therapeutic agent for the treatment of acute promyelocytic leukemia [39]. In addition, ATO can suppress the progression in many solid tumors such as breast, colon, and liver [40-42]. We previous revealed that a relative lower concentration of ATO effectively attenuated migration/invasion, angiogenesis, and self-renewal in HCC cells [27, 28, 43]. Moreover, a recent clinical study revealed that there is a

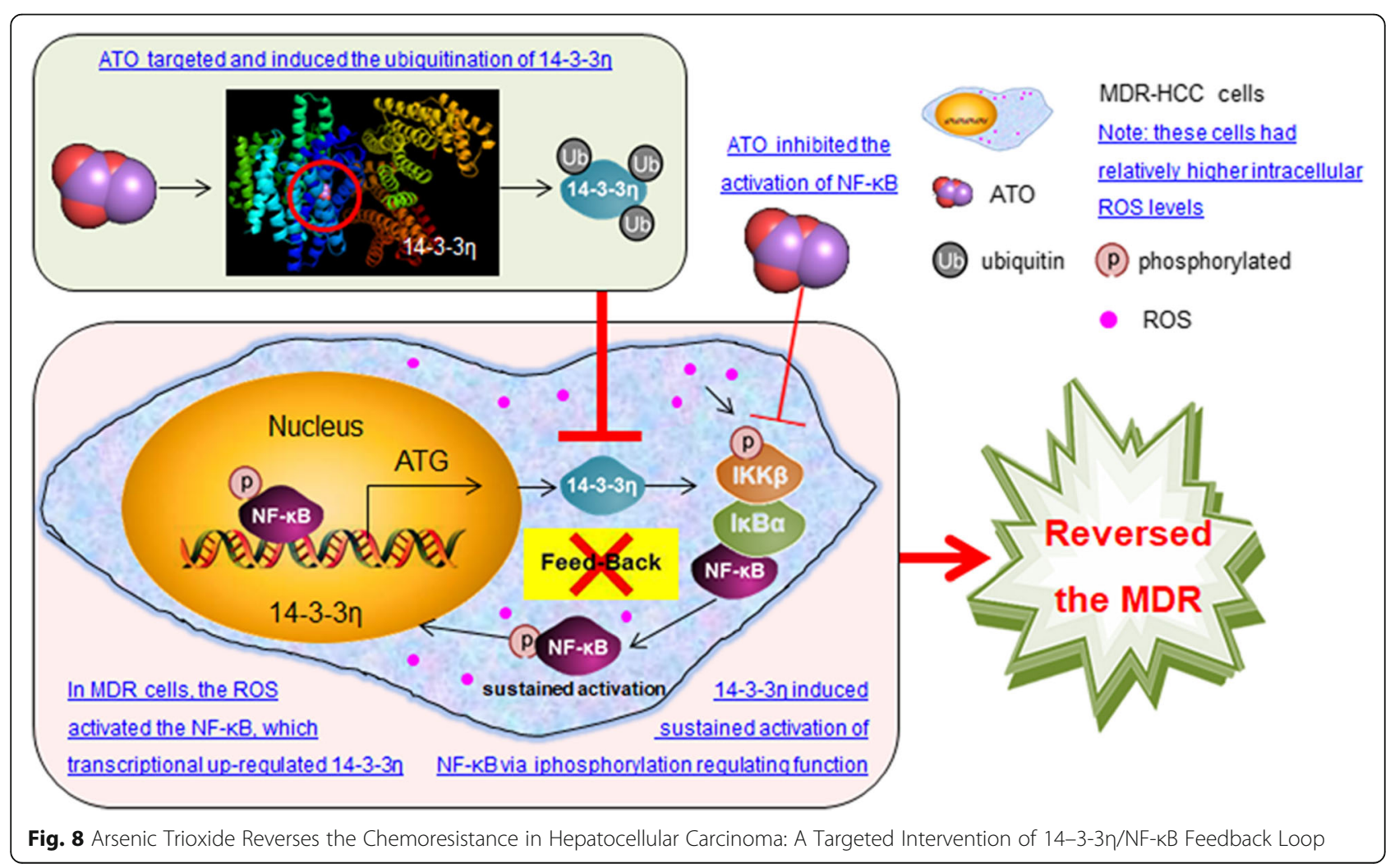


relatively prolonged overall/recurrence-free survival ratio in those patients treated with TACE plus an intravenous infusion of ATO in comparison with patients receiving TACE therapy alone [44]. Further, ATO can facilitate the anti-cancer activities of sorafenib in HCC cells [45]. In the rabbit HCC model, studies reveal that TACE used in combination with ATO had potent anticancer effects without significant hepatic or renal toxicities [46, 47]. Indeed, ATO has been approved for the treatment of human primary HCC by the State Food and Drug Administration of China [48, 49]. In addition, unlike other chemotherapy drugs, ATO has been recognized as a molecular targeted drug in the "Standard for Diagnosis and Treatment of Primary HCC in China (2017)", as it can target and in turn induce the degradation of PML-RAR protein [29]. Here, we found that $14-3-3 \eta$ played an important role in inducing/maintaining the antioxidation/MDR state. Nevertheless, there is no identified inhibitor for $14-3-3 \eta$ up to date, so our present study suggested for the first time that

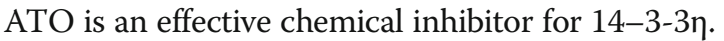

\section{Conclusion}

In conclusion, Bel/5-Fu cells exhibited a relative higher level of ROS, which activated NF- $k B$, leading to the transcriptionally up-regulation of $14-3-3 \eta$. NF- $\mathrm{kB} / 14-3-3 \eta$ can form a positive feed-back loop to induce/maintain the MDR phenotype in HCC cells. ATO could abolish this feed-back loop by either blocking of NF- $\mathrm{kB}$ signaling and $14-3-3 \eta$ transcription, or by targeting $14-3-3 \eta$ for its ubiquitination and degradation. These processes abolished the antioxidation mechanisms employed by Bel/ 5-Fu cells and reversed the MDR (Fig. 8).

\section{Additional file}

Additional file 1: Arsenic Trioxide Reverses the Chemoresistance in Hepatocellular Carcinoma: A Targeted Intervention of 14-3-3n/NF-KB Feedback Loop. (PDF 397 kb)

\section{Abbreviations}

ATO: Arsenic trioxide; HCC: Hepatocellular carcinoma; MDR: Multi-drug resistance; NF-KB: Nuclear factor kappa B; ROS: Reactive oxygen species

\section{Acknowledgements}

Not applicable.

\section{Funding}

This work was supported by the National Natural Science Foundation of China $(81572325,81602841$, and 81874058), the Natural Science Foundation of Jiangsu Province (BK20161570), the Project Funded by Jiangsu Collaborative Innovation Center For Cancer Personalized Medicine (JX21817902/006), the Project Funded by Jiangsu Postgraduate Research and Innovation Plan (KYCX18_1491), and the International Exchange and Cooperation Program Funded by Nanjing Medical University (C102).

Availability of data and materials Not applicable.

\section{Authors' contributions}

$Y L, J Z, W W$, and ZJ conceived the research. YQ and Yi Dai drafted the manuscript. WW, ZJ, GH, and LY reviewed and revised it critically. YQ, YD, CZ, $J S, L J, Y W, R J$, and $Y X$ performed cell experiments. YY, MJ, WS, ML, and ZT carried out the sample preparation, IP-AFS analysis and data interpretation. All the authors have read and approved the final version of the manuscript. $Y Q, Y D, C Z, Y Y$, and MJ contributed equally to this work.

Ethics approval and consent to participate

Not applicable.

\section{Consent for publication}

Not applicable.

\section{Competing interests}

The authors declare that they have no competing interests.

\section{Publisher's Note}

Springer Nature remains neutral with regard to jurisdictional claims in published maps and institutional affiliations.

Received: 17 October 2018 Accepted: 14 December 2018

Published online: 20 December 2018

\section{References}

1. Dutta R, Mahato RI. Recent advances in hepatocellular carcinoma therapy. Pharmacol Ther. 2017;173:106-17.

2. Kuczynski EA, et al. Co-option of Liver Vessels and Not Sprouting Angiogenesis Drives Acquired Sorafenib Resistance in Hepatocellular Carcinoma. J Natl Cancer Inst. 2016;108(8):djw030.

3. Dhir M, et al. A review and update of treatment options and controversies in the management of hepatocellular carcinoma. Ann Surg. 2016;263(6): $1112-25$.

4. Fornari F, et al. In hepatocellular carcinoma miR-221 modulates Sorafenib resistance through inhibition of Caspase-3-mediated apoptosis. Clin Cancer Res. 2017:23(14):3953-65.

5. Poillet-Perez L, et al. Interplay between ROS and autophagy in cancer cells, from tumor initiation to cancer therapy. Redox Biol. 2015;4:184-92.

6. Xia $\mathrm{H}$, et al. pH-sensitive Pt Nanocluster assembly overcomes Cisplatin resistance and heterogeneous Stemness of hepatocellular carcinoma. ACS Cent Sci. 2016;2(11):802-11.

7. Zhao J, et al. 14-3-3 proteins as potential therapeutic targets. Semin Cell Dev Biol. 2011:22(7):705-12.

8. Lee YK, et al. Knockdown of 14-3-3zeta enhances radiosensitivity and radioinduced apoptosis in CD133(+) liver cancer stem cells. Exp Mol Med. 2014; 46:e77.

9. Wu YJ, et al. Involvement of 14-3-3 proteins in regulating tumor progression of hepatocellular carcinoma. Cancers (Basel). 2015;7(2):1022-36.

10. Huang XY, et al. alphaB-crystallin complexes with 14-3-3zeta to induce epithelial-mesenchymal transition and resistance to sorafenib in hepatocellular carcinoma. Hepatology. 2013;57(6):2235-47.

11. Reis H, et al. A structured proteomic approach identifies 14-3-3Sigma as a novel and reliable protein biomarker in panel based differential diagnostics of liver tumors. Biochim Biophys Acta. 2015;1854(6):641-50.

12. Shen J, et al. 14-3-3eta is a novel growth-promoting and angiogenic factor in hepatocellular carcinoma. J Hepatol. 2016;65(5):953-62.

13. Uchibori $\mathrm{K}$, et al. Establishment and characterization of two 5-fluorouracilresistant hepatocellular carcinoma cell lines. Int J Oncol. 2012:40(4):1005-10.

14. Zhang $Y$, et al. Nestin overexpression in hepatocellular carcinoma associates with epithelial-mesenchymal transition and chemoresistance. J Exp Clin Cancer Res. 2016;35(1):111

15. Lu F, et al. TFPI-2 downregulates multidrug resistance protein in 5-FUresistant human hepatocellular carcinoma BEL-7402/5-FU cells. Anat Rec. 2013;296(1):56-63.

16. Li Y, et al. Mot-2-mediated cross talk between nuclear factor-B and p53 is involved in arsenite-induced tumorigenesis of human embryo lung fibroblast cells. Environ Health Perspect. 2010;118(7):936-42.

17. Ling $M$, et al. Regulation of miRNA-21 by reactive oxygen species-activated ERK/NF-kappaB in arsenite-induced cell transformation. Free Radic Biol Med. 2012;52(9):1508-18. 
18. Zhu D, et al. The ROS-mediated activation of STAT-3/NEGF signaling is involved in the 27-hydroxycholesterol-induced angiogenesis in human breast cancer cells. Toxicol Lett. 2016;264:79-86.

19. Liu J, et al. The ROS-mediated activation of IL-6/STAT3 signaling pathway is involved in the 27-hydroxycholesterol-induced cellular senescence in nerve cells. Toxicol in Vitro. 2017:45(Pt 1):10-8.

20. Li Y, et al. The repressive effect of NF-kappaB on p53 by mot-2 is involved in human keratinocyte transformation induced by low levels of arsenite. Toxicol Sci. 2010;116(1):174-82

21. Li Y, et al. Opposed arsenite-mediated regulation of p53-survivin is involved in neoplastic transformation, DNA damage, or apoptosis in human keratinocytes. Toxicology. 2012;300(3):121-31.

22. Marie-Egyptienne DT, Lohse I, Hill RP. Cancer stem cells, the epithelial to mesenchymal transition (EMT) and radioresistance: potential role of hypoxia. Cancer Lett. 2013;341(1):63-72.

23. Le Grazie $M$, et al. Chemotherapy for hepatocellular carcinoma: the present and the future. World J Hepatol. 2017;9(21):907-20.

24. Ikeda M, et al. Systemic chemotherapy for advanced hepatocellular carcinoma: past, present, and future. Diseases. 2015;3(4):360-81.

25. Ko BS, et al. Upregulation of focal adhesion kinase by 14-3-3epsilon via NFkappaB activation in hepatocellular carcinoma. Anti Cancer Agents Med Chem. 2013;13(4):555-62.

26. Tang $Y$, et al. 14-3-3zeta up-regulates hypoxia-inducible factor-1alpha in hepatocellular carcinoma via activation of PI3K/Akt/NF-small ka, CyrillicB signal transduction pathway. Int J Clin Exp Pathol. 2015;8(12):15845-53.

27. Wang $X$, et al. Arsenic trioxide attenuates the invasion potential of human liver cancer cells through the demethylation-activated microRNA-491. Toxicol Lett. 2014;227(2):75-83.

28. Jiang F, et al. Inhibition of TGF-beta/SMAD3/NF-kappaB signaling by microRNA-491 is involved in arsenic trioxide-induced anti-angiogenesis in hepatocellular carcinoma cells. Toxicol Lett. 2014;231(1):55-61.

29. Zhang XW, et al. Arsenic trioxide controls the fate of the PML-RARalpha oncoprotein by directly binding PML. Science. 2010;328(5975):240-3.

30. Ghavamzadeh A, et al. Treatment of acute promyelocytic leukemia with arsenic trioxide without ATRA and/or chemotherapy. Ann Oncol. 2006;17(1): $131-4$.

31. Longley DB, Harkin DP, Johnston PG. 5-fluorouracil: mechanisms of action and clinical strategies. Nat Rev Cancer. 2003;3(5):330-8.

32. Kelland $L$. The resurgence of platinum-based cancer chemotherapy. Nat Rev Cancer. 2007:7(8):573-84

33. Gorini $\mathrm{S}$, et al. Chemotherapeutic drugs and mitochondrial dysfunction: focus on doxorubicin, Trastuzumab, and Sunitinib. Oxidative Med Cell Longev. 2018;2018:7582730.

34. Wei X, et al. Light-activated ROS-responsive Nanoplatform Codelivering Apatinib and doxorubicin for enhanced chemo-photodynamic therapy of multidrug-resistant tumors. ACS Appl Mater Interfaces. 2018;10(21):17672-84.

35. Chen HY, et al. Regulation of tNOX expression through the ROS-p53POU3F2 axis contributes to cellular responses against oxaliplatin in human colon cancer cells. J Exp Clin Cancer Res. 2018;37.

36. Karin M. Nuclear factor-kappaB in cancer development and progression. Nature. 2006;441(7092):431-6.

37. Basseres DS, Baldwin AS. Nuclear factor-kappaB and inhibitor of kappaB kinase pathways in oncogenic initiation and progression. Oncogene. 2006; 25(51):6817-30.

38. Tanaka K, et al. Oncogenic EGFR signaling activates an mTORC2-NF-kappaB pathway that promotes chemotherapy resistance. Cancer Discov. 2011;1(6): 524-38.

39. Cicconi L, Lo-Coco F. Current management of newly diagnosed acute promyelocytic leukemia. Ann Oncol. 2016;27(8):1474-81.

40. Ahn RW, et al. A novel nanoparticulate formulation of arsenic trioxide with enhanced therapeutic efficacy in a murine model of breast cancer. Clin Cancer Res. 2010;16(14):3607-17.

41. Thomas-Schoemann A, et al. Arsenic trioxide exerts antitumor activity through regulatory $T$ cell depletion mediated by oxidative stress in a murine model of colon cancer. J Immunol. 2012;189(11):5171-7.

42. Zhang $X$, et al. Promyelocytic leukemia protein induces arsenic trioxide resistance through regulation of aldehyde dehydrogenase 3 family member A1 in hepatocellular carcinoma. Cancer Lett. 2015;366(1):112-22.

43. Li Y, et al. Inhibition of the cancer stem cells-like properties by arsenic trioxide, involved in the attenuation of endogenous transforming growth factor beta signal. Toxicol Sci. 2015;143(1):156-64.
44. Hu HT, et al. Arsenic trioxide intravenous infusion combined with transcatheter arterial chemoembolization for the treatment of hepatocellular carcinoma with pulmonary metastasis: long-term outcome analysis. J Gastroenterol Hepatol. 2017;32(2):295-300.

45. Zhai $B$, et al. Arsenic trioxide potentiates the anti-cancer activities of sorafenib against hepatocellular carcinoma by inhibiting Akt activation. Tumour Biol. 2015;36(4):2323-34.

46. Kim HJ, et al. Efficacy of transarterial embolization with arsenic trioxide oil emulsion in a rabbit VX2 liver tumor model. J Vasc Interv Radiol. 2009;20: 1365-70.

47. Yu H, et al. Arterial embolization hyperthermia using As2O3 nanoparticles in VX2 carcinoma-induced liver tumors. PLoS One. 2011;6:e17926.

48. Hu HT, et al. Arsenic trioxide intravenous infusion combined with transcatheter arterial chemoembolization for the treatment of hepatocellular carcinoma with pulmonary metastasis: Longterm outcome analysis. J Gastroen Hepatol. 2017;32:295-300.

49. Lv XH, et al. Arsenic trioxide combined with transarterial chemoembolization for primary liver cancer: a meta-analysis. J Gastroen Hepatol. 2017;32:1540-7.

\section{Ready to submit your research? Choose BMC and benefit from:}

- fast, convenient online submission

- thorough peer review by experienced researchers in your field

- rapid publication on acceptance

- support for research data, including large and complex data types

- gold Open Access which fosters wider collaboration and increased citations

- maximum visibility for your research: over $100 \mathrm{M}$ website views per year

At BMC, research is always in progress.

Learn more biomedcentral.com/submissions 